\title{
Predicting human behaviour: Is free will an illusion or a reality?
}

\author{
Olivia Murphy ${ }^{1}$ \\ ${ }^{1}$ RMIT University
}

May 5, 2020

Olivia J. Murphy

Submitted 9 Mar 2020

1085 words

Conscious will may be the cause of an action or the apparent cause of an action. Determinism states that it is the latter, whereas free will states the opposite (Wegner, D.M., 2002). Determinism implies that humans are not in control of their actions, but rather under the illusion that they have control. Both sides of the debate offer credible evidence, but much of the results from research in this area are still inconclusive. For example, it is not possible to determine which area of the brain the experience of will occurs at (Wegner, D.M., 2002). Therefore, it is difficult to determine the true nature of the cause of an individual's actions. However, it is possible that free will and determinism co-occur equally or at differing percentages. That is, human actions may be due to an individual's thoughts as well as predetermined factors that one is unaware of. If the actions of humans are indeed predetermined, then it becomes possible to accurately predict the decisions that a person will make. On the other hand, if free will truly exists alone, then actions would be unpredictable by a third party. Lifetime events may be easier to predict than daily events. It is dependent on the certainty with which one can conclude that an event is predetermined. There are many variables that affect this certainty, including dispositional and situational factors.

Dispositional factors having a large impact on human behaviour would support the notion of determinism. Zautra A. J. et al. (1991) showed that personality has little to do with the causation of daily events in older adults, suggesting that actions may be triggered by thoughts and are not predetermined. Contrary to this notion, it has been shown that psychological stress levels can be anticipated by personality in people of all ages, helping to predict major life events such as depressive episodes (Kendler, K. S. et al., 2004). It is possible, however, that the personality that correlates with the depressive episodes is a result of the depressive episodes rather than the cause of them. If this is the case, then personality would be ruled out as a significant indicator of psychological stress. However, this does not account for factors such as context, which may also play a role in determining a person's behaviour. Situational factors may determine how well a person copes with life as well as whether a female will confront gender discrimination or not (Ayres, M. M. et al., 2009; Fabes, R. A., \& Eisenberg, N., 1997). This proves that although dispositional factors may be a weak predictor of daily life events, this is not the case for situational factors. Everyday behaviour in students in particular has been shown to be strongly influenced by situational factors including positive reinforcement and availability of support services (Jackson, Y., \& Warren, J. S., 2000). It seems that context is an important predictor of behaviour for children and adults. Other than these internal and external factors, other causal factors exist in the anticipation of human behaviour.

Wegner (2002) lists a number of "alternatives to thoughts as causes for actions" such as impulse and emotion. From this, he endeavours to explain that actions which are due to strong emotion lack voluntariness. Furthermore, he implies that actions are not largely a result of our thoughts and that we are being deceived 
when we attribute our actions to free will. On the contrary, it is very possible that impulsive actions, including those that are widely accepted as involuntary such as yawning, may be partly or largely voluntary. One could argue that emotions are heavily driven by our thoughts. Nussbaum (2001) goes as far as to refer to emotions as "upheavals of thoughts". This would suggest that impulsive actions, which are due to emotions, are in fact due to intense thoughts. Thoughts may therefore be the cause of impulsive actions which may make these actions partly voluntary. Additionally, those with Autism Spectrum Disorder are said to struggle when it comes to feeling empathy (Department of Life, Health and Environmental Sciences, University of L'Aquila, 2014). As well as this, they are significantly less likely to yawn contagiously (Senju, A. et al., 2007). Furthermore, it is believed by some that yawning may be largely due to feelings of empathy (Palagi, E. et al., 2009). It can be construed from this that yawning, an impulsive action, may be caused by an "upheaval of thoughts" (Nussbaum, M.C., 2003), making it a voluntary action. However, this would not be labelled as part of conscious free will, as we are unaware of the appearance of the urge to yawn before it appears (Wegner 2020). The evidence supports the notion that there may be merit to both the impression that we have control over our actions and the impression that it is actually an illusion. Therefore, actions may be partially under an individual's own conscious control, and partially unconscious. However, other research suggests otherwise.

The order of events when performing an action is crucial when it comes to the debate of determinism and free will. If conscious will were to be experienced prior to the biological processes involved in acting out a movement, then free will would likely be a reality. On the other hand, if research were to show that the body prepares for action even milliseconds before the individual becomes aware of deciding to perform that action, then it would be very likely that all actions are indeed predetermined. In reality, the latter appears to be true, as "conscious will kicks in after the brain has already started preparing for the action" (Wegner, 2002). This strongly points to determinism and could completely rule out the possibility that free will exists. However, there have been little replications of the experiment used to unearth this evidence and therefore its credibility can be questioned (Wegner, 2002). It seems that although research strongly suggests predetermination of actions, more research is required to stabilize the determinism claim and determine if human behaviour can in fact be predicted accurately.

It is clear that there is not enough evidence to conclude whether free will exists or not. Further research is required to determine to what length the behaviour of others can be predicted and how accurate these predictions can be. Evidence points towards a combination of predeterminism and conscious choice, which suggests that some behaviour can be predicted. In particular, external factors influence the daily life events of individuals and allow us to make predictions, whilst internal factors are possibly an influence for major life events.

Ayres, M. M., Friedman, C. K., \& Leaper, C. (2009). Individual and situational factors related to young women's likelihood of confronting sexism in their everyday lives. Sex Roles , 61 . doi.: 10.1007/s11199-0099635-3

Department of Life, Health and Environmental Sciences, University of L'Aquila. (2014). Affective and cognitive empathy in adolescents with autism spectrum disorder. Frontiers, 8 . doi.: 10.3389/fnhum.2014.00791

Fabes, R. A., \& Eisenberg, N. (1997). Regulatory control and adults' stress-related responses to daily life events. Journal of personality and social psychology, 73 . doi.: 10.1037/0022-3514.73.5.1107

Jackson, Y., \& Warren, J. S. (2000). Appraisal, social support, and life events: Predicting outcome behavior in school-age children. Child development , 71 . doi.: 10.1111/1467-8624.00238

Kendler, K. S., Kuhn, J., \& Prescott, C. A. (2004). The interrelationship of neuroticism, sex, and stressful life events in the prediction of episodes of major depression. American Journal of Psychiatry , 161 . doi.: 10.1176/appi.ajp.161.4.631

Nussbaum, M.C. (2003). Upheavals of thought: The intelligence of emotion . (pg. 2). Cambridge University Press. 
Palagi, E., Leone, A., Mancini, G., \& Ferrari, P.F. (2009). Contagious yawning in gelada baboons as a possible expression of empathy.Proceedings of the National Academy of Sciences of the United States of America, 46 . doi.: 10.1073/pnas.0910891106

Senju, A., Maeda, M., Kikuchi, Y., Hasegawa, T., Tojo, Y., \& Osanai, H. (2007). Absence of contagious yawning in children with Autism Spectrum Disorder. The Royal Society Publishing, 6 . doi.: $10.1098 /$ rsbl.2007.0337

Wegner, D.M. (2002). The illusion of conscious will . Massachusetts Institute of Technology.

Zautra A. J., Finch, J.F., Reich, J.W., \& Guamaccia, C.A. (1991). Predicting the everyday life events of older adults. Journal of Personality, 59 . doi.: 10.1111/j.1467-6494.1991.tb00258.x 